\title{
A3 ENTRE a casa e a fÁbrica: MEMÓRIAS do www.aibr.org TRABALHO OPERÁRIO NO FEMININO
}

\section{Sónia Ferreira}

Investigadora, Centro de Estudos de Etnologia Portuguesa, Faculdade de Ciências Sociais e Humanas, Universidade Nova de Lisboa (Portugal).

\section{Resumo}

Pretende-se abordar a forma como algumas operárias da Margem Sul, de Almada em particular, constroem as suas memórias do trabalho fabril. Estas cruzam o tempo privado e o tempo público, pois se é através da memória familiar que muitas vezes constroem o eixo do relato biográfico, este nunca se encontra desligado da memória do trabalho.

Neste universo feminino, quer o trabalho formal remunerado quer o doméstico são realizados de forma entrecruzada, num aproveitamento exaustivo do tempo. O espaço da fábrica poderia ser utilizado para a realização de tarefas domésticas, assim como o espaço privado da casa para o trabalho fabril, que era levado para fazer ao serão em regime de empreitada. Ambos os espaços se conjugam num intercâmbio de actividades que produz memórias profissionais particularmente flexíveis e muito pouco compartimentadas.

\section{Palavras chave}

Memória, mulheres, operariado, trabalho

\begin{abstract}
In this article I intend to approach the way some feminine workers from the South of Lisbon, particularly in Almada, built up their industrial working memories. They mix private and public time, because if it's through the family memories that they built the axis of the biographical discourse, this is never disconnected from the work memories.

In this feminine universe, both formal paid and domestic work cross each other in a profitable use of time. The factory working space could be used to do domestic work as the private home space to do factory work (carried to be done at night in piece-work regime). Both spaces are united in a changing process of activities that produce work memories particularly flexible and linked to each other.
\end{abstract}

Key words

Memory, women, work, workers 


\section{Introdução}

W presente artigo centrar-me-ei nas memórias do trabalho operário feminino, tendo por estudo principalmente a forma como as minhas informantes constróem e partilham as suas memórias profissionais, entendendo este conceito no sentido de Halbwachs e da dicotomia memória individual e memória social e/ou colectiva e também de Namer (1987), numa abordagem mais contemporânea e revista do quadro clássico do "pai" da "memória colectiva".

Ao partir da utilização de histórias de vida, procurando no individual o colectivo, pretendi ir de encontro ao que Halbwachs propõe quando diz que cada memória individual é um ponto de vista sobre a memória colectiva e que esse ponto de vista muda conforme o lugar que eu ocupo na sociedade, assim como esse mesmo lugar não é estático e está dependente das relações que eu mantenha com os diferentes grupos sociais (Halbwachs, 1997:94-95).

Assim, terei um mosaico de memórias mais ou menos convergentes sobre a mesma realidade, embora ao mesmo tempo diferentes e contextuais.

Por fim, não será de descurar a divisão que Halbwachs (1997: 85-91) faz entre a memória dos nobres, em declínio, e as formas contemporâneas de memórias de classe, associadas à classe operária e à burguesia, consequência da divisão social do trabalho. Assim, a uma memória que durante muito tempo foi também a memória da nação, seguem-se memórias isoladas, anómicas, centrífugas onde o homem se confunde com a sua profissão e não é simplesmente mais um instrumento, mas sim um elemento, uma parte integrante da própria substância da sociedade (1925: 231). Trata-se de uma memória-saber, sedimentada na prática.

Em termos metodológicos, a utilização dos relatos orais, especialmente no formato de história de vida, aparece na antropologia por volta dos anos 20 , onde levanta questões próprias e interrogações particulares, embora a sua utilização, enquanto método biográfico, não seja exclusivo desta ciência. Em primeiro lugar, o acesso e a reprodução da experiência e da voz do Outro parece caracterizar uma apetência ocidental pelo exótico, já que desde os primeiros trabalhos de recolha de histórias de vida junto de comunidades índias norte-americanas suscitou o interesse e curiosidade do público que, como dizem Langness e Frank (1995: 17, tradução própria): “(...) parece ter-se sempre interessado pelas vidas dos desviantes ou das pessoas pouco comuns de qualquer tipo". Também o redireccionar do olhar antropológico para o exótico perto de casa, o leva a estudar grupos e sub-culturas considerados menores ou marginais, numa tentativa de incorporar aspectos até então negligenciados da vida social. Exemplos destes trabalhos podem ser encontrados junto dos autores ligados, por exemplo, à Escola de Chicago, essencialmente na visibilidade dada aos grupos excluídos e marginais, e também nos trabalhos produzidos por autoras identificadas com as correntes feministas no que posteriormente se designará por Women Studies: "As histórias de vida de mulheres 
aumentaram em número nos últimos anos, devendo-se este aumento essencialmente à tentativa de retratar o que era tradicionalmente considerado um aspecto negligenciado da cultura" (Langness e Frank, 1995: 27, tradução própria).

Paul Thompson, na sua obra sobre história oral , onde pretende instruir os historiadores na recolha e tratamento de fontes orais, chama também a atenção para o florescer de poder da classe operária, no pós $2^{\mathrm{a}}$ Guerra Mundial, que conduz ao interesse pela história das classes trabalhadoras. Este interesse vai materializar-se, por exemplo, em autobiografias e recolhas de depoimentos que são utilizados quer na produção literária e científica, quer na programação audiovisual em televisão, através de séries de ficção ou documentais. Esta nova corrente, no seio da sociologia dos anos 50 , preocupava-se essencialmente, segundo Thompson, já não apenas com a pobreza, mas com a "cultura da classe operária e da comunidade em si" (Thompson, 1988:64, tradução própria). O autor enumera algumas das vertentes que a história oral no âmbito das classes trabalhadoras pode assumir, como por exemplo, a evolução de uma organização ou de uma greve específica, estudos de comunidade, o trabalho e as relações sociais resultantes deste, etc. Concluindo que a história oral "pode ir para além das formalidades e dos heroísmos das afirmações de liderança, como se pode ver representado na imprensa e noutros registos, chegando a uma realidade mais banal e confusa com diferentes pontos de vista por parte dos participantes [rank and file], incluindo os traidores [blacklegs]" (1988: 80, tradução própria).

Contudo, apesar deste interesse generalizado por parte quer da academia quer do público em geral, as mulheres trabalhadoras continuam a ser amplamente ignoradas, o que se deve ao facto de a sua vida ser essencialmente "indocumentada", com laços mais frágeis com o mundo laboral e outras instituições sociais formais do domínio público (1988: 97). Sendo por isso necessário redireccionar o olhar científico também para temas menos visíveis do espaço social público.

\section{As Mulheres e as Fábricas}

Em Almada, durante a primeira metade do século $X X$, a indústria corticeira é a que emprega mais mão-de-obra feminina. No entanto, também existiam mulheres a trabalhar nas conservas, na preparação de redes de pesca, nos armazéns de vinho e azeite, na moagem, entre outras indústrias, embora nunca em tão grande número como nas duas maiores fábricas de cortiça: a Rankin \& Sons e a Henry Bucknall \& Sons. Algumas destas mulheres entravam para as fábricas muito novas, com treze, catorze anos, outras passavam primeiro por oficinas mais pequenas e de ofícios mais tradicionais em que como aprendizes lhes era ensinada, por exemplo, a profissão de costureira, que era inegavelmente na época considerada a que mais se coadunava com uma pretensa actividade laboral de carácter feminino: "Faziam todos os possíveis para as pôr na costura. Uma das coisas assim aqui na Piedade que era uma coroa de glória, era as famílias meterem as filhas no Luciano que era um alfaiate, aqui à ponte do Caramujo" (ML - empregado de escritório - 76 anos ). 
A pluriactividade é um fenómeno constante na actividade quotidiana destas mulheres, assim como da comunidade operária em geral . O carácter cumulativo de pelo menos duas actividades remuneradas é entendido como indispensável para a manutenção do agregado familiar. Esta forma de gestão dos recursos disponíveis reveste-se também para comunidade de um carácter valorativo de demonstração de uma personalidade ligada ao trabalho, "não ter medo de enfrentar a vida", não se sentir "assustado pelo trabalho", "ser muito amiga de trabalhar", "saber governar a vida" são algumas das expressões que caracterizam os discursos. Sally Cole em Mulheres da Praia, revela-nos o mesmo sobre uma comunidade piscatória a norte do país: "A socialização das raparigas das famílias de pescadores era feita através do seu papel de trabalhadeira. O termo trabalhadeira define uma mulher que é laboriosa, poupada e habilidosa na gestão dos recursos familiares" (Cole, 1994: 99), sendo esta uma característica que se reveste de extrema importância no mercado matrimonial . Elizabeth Roberts, na obra A Woman's Place: an oral history of working-class women. 1890-1940, relata o mesmo acerca da moral do trabalho, numa Inglaterra impregnada de valores vitorianos: "as crianças das classes trabalhadoras eram educadas na crença de que o trabalho árduo era vitalmente necessário, não só para a sobrevivência do indivíduo e da família mas como possuindo em si um valor moral intrínseco" (Roberts, 1984: 51, tradução própria).

Quase todas as operárias que entrevistei também descrevem quotidianos marcados pela pluriactividade:

A gente vinha de lá [da fábrica da cortiça] e ainda íamos fazer serão para a fábrica de peixe. (...) Havia apitos e a gente conhecia os apitos do peixe. (...) Havia mais fábricas de peixe. Havia uma lá em baixo no Caramujo que era ao pé da farinha, muitas saíam da fábrica da cortiça e iam logo para ali (CR - corticeira - 92 anos ); lam por exemplo para os fabricos, trabalhava-se as oito horas por exemplo no Rankin, na Companhia ou no Cabruja e depois ia-se a partir das cinco trabalhar para os fabricos (JF - corticeira - 85 anos)

A definição da idade com que se começa a trabalhar é outro factor de análise importante, não só demonstrativo dos processos de mudança social que fazem com que hoje este comportamento, de aceitar trabalhadores entendidos como crianças, seja socialmente criticável, analisado e legislado pelas organizações mundiais e entendido como um fenómeno ligado ao sub-desenvolvimento, à pobreza e à barbárie, mas também como processo definidor das etapas do ciclo de vida. A entrada no mundo do trabalho surge geralmente enquadrada por duas vertentes: a primeira, as condições objectivas de pobreza que "empurram" o indivíduo para o domínio da capacidade de gerar riqueza para o agregado familiar e depois porque esta realidade do trabalho faz parte do quotidiano das famílias operárias, gerando comportamentos miméticos nos membros mais novos. John Gillis diferencia o adolescente, fenómeno da classe média, e os homens/crianças pertencentes às classes operárias. O autor (1974: 40) considera que é a pobreza o factor mais importante na definição do ciclo de vida de um jovem pertencente a uma família operária. Também estas mulheres querem maioritariamente ir para a fábrica por questões de subsistência e escolhem precisamente a área de trabalho com que sempre conviveram quotidianamente, onde possuem redes sociais e familiares. Assim, parecem entrar no mercado de trabalho motivadas mais pelas necessidades económicas do que por qualquer outra motivação emancipatória relacionada por exemplo com a libertação da mulher (Roberts, 1984: 138). Até porque ser "fabricanta", não era uma posição socialmente invejável. 
Também Ana Nunes de Almeida (1993: 55), num trabalho sobre as famílias operárias no Barreiro, vai percepcionar esta realidade:

\begin{abstract}
[O] trabalho feminino na fábrica só muito raramente é uma experiência de emancipação ou estritamente individual enquadra-se, pelo contrário, e segundo uma lógica tradicional, na estratégia de sobrevivência das famílias das classes trabalhadoras em meio industrial. Resulta, portanto, das necessidades económicas dum grupo doméstico e não de um desejo pessoal feminino.
\end{abstract}

Até porque a saída de casa das mulheres não as alivia das obrigações domésticas, nem as coloca numa situação de paridade com o poder paternal ou marital.

Quanto às suas memórias profissionais, passam a ser construídas a partir de um novo calendário, incorporando um tempo e também um espaço que será estruturador da evocação. Ao entrarem para a fábrica, ao se tornarem operárias, estas mulheres adquirem ritmos quotidianos totalmente determinados pelos horários da produção fabril (Luzia, 1996: 50): "Na análise da construção do tempo constata-se que o trabalho fabril é determinante na concepção da compartimentação de tempo diário, enquanto permite uma noção mais apurada da cronologia, ou seja do tempo histórico". Tempo privado e tempo público cruzam-se na percepção e descrição dos quotidianos do passado. Em termos cíclicos mais gerais a entrada ou saída da fábrica, pelo menos nos casos de maior estabilidade e durabilidade num único estabelecimento, marca uma etapa importante e muitas vezes bem recordada do ciclo de vida: "No Rank, com treze anos, 1930. Quando comecei. E lembro-me que foi a 5 de Outubro, veja lá, eu tenho quase oitenta e seis anos" (RG - corticeira - 86 anos); "Entrei para lá [para a Sociedade de Reparação de Navios] com 16 anos em Junho, no dia 4 de Junho de 1944, nunca me esqueceu" (BR - emalhadora de redes - 75 anos).

Françoise Zonabend (1980), no seu trabalho sobre a "memória longa" em Minot, também nos fala da importância que os rituais ligados aos ciclos de vida, rituais de passagem associados por exemplo à família, assumem no papel de organizadores do passado, da História. Nos relatos das operárias de Almada é também através desta memória familiar que elas muitas vezes constróem o eixo do relato biográfico, embora este nunca se encontre desligado da memória do trabalho: "Eu fui para lá com treze, saí de lá tinha o meu H... três anos, ele nasceu em 43, parece que foi, já nem sei bem. Casei em 37, depois nasceu a M.... Ele nasceu só dali a seis anos, portanto 44 (...)" (GC - corticeira - 79 anos) .

Aliás, é sobre o entrecruzamento das duas realidades que nos surgem relatos pois, no universo feminino em particular, o trabalho remunerado e doméstico é realizado quase em simultâneo, num aproveitamento exaustivo do tempo: "A hora do almoço era para fazer o que tínhamos que fazer, às vezes ia às compras à praça, não tínhamos tempo para almoçar nem coisa nenhuma" (EA - corticeira - 82 anos); "À hora de almoço se havíamos de estar a comer, muitas das vezes ia-mos pô-la [a roupa] em sabão, púnhamos um bocadinho de sabão e deixávamos ficar" (CR - corticeira - 92 anos). As mulheres eram as gestoras do lar: dos filhos ao serviço doméstico, da alimentação às compras eram elas que organizavam e geriam o quotidiano familiar. Ele está sempre presente nas suas 
mentes e nos seus discursos. Apesar dos horários rígidos das fábricas e das muitas horas que lá passavam, elas conseguiam prover a realização de ambas as actividades através de uma articulação complexa do tempo. Estas predecessoras das mulheres dos tempos modernos, a quem faltava os recursos da tecnologia actual, dividiam-se pela realização de tarefas profissionais e domésticas de forma intercalada ou contínua ao longo do dia:

\begin{abstract}
Tinha o hábito de ir lavar roupa à hora do almoço, eu e muitas, vínhamos à praça da Cova da Piedade a correr, quando lavávamos alguma roupa nos tanques da Romeira púnhamos a secar no casal em cima dos fardos da cortiça e à hora da saída já estava enxuta. De modo que eu comia pouco no refeitório. Quando vínhamos desses afazeres já era mais tarde, ainda dentro da hora do almoço, e sentávamo-nos numa mesa que havia na cozinha. Mas era proibido" (GC - corticeira - 79 anos) .
\end{abstract}

Até os momentos de greve eram aproveitados: "A gente estava de greve, cada qual estava na sua máquina, não se trabalhava, levava-se meias para cozer ou isto ou aquilo" (JF - corticeira - 85 anos). O próprio espaço da fábrica era assim utilizado para a realização de tarefas domésticas, embora o espaço privado da casa também fosse utilizado para o trabalho fabril, quando levavam tarefas para fazer ao serão em regime de empreitada. Ambos os espaços se conjugam num intercâmbio de actividades.

Um outro aspecto vivamente recordado da fábrica é a faceta lúdica do relacionamento entre colegas, embora a maior parte destas acções fossem marcadas pela clandestinidade: "A gente não podia fazer brincadeiras à vista de ninguém, era sempre a fugir e a correr" (EA - corticeira - 85 anos). O "fazer às escondidas" é a marca do quotidiano que aguça o espírito e deixa lembranças duradouras. O relato das brincadeiras serve também de contraponto às descrições da pobreza, dos medos, do quotidiano de miséria material, pois mesmo assim: "Andávamos felizes, já viu! (...) E sempre alegres, a gente pelo caminho [da Charneca da Caparica], rapazes e raparigas, andávamos sempre bem dispostos, a falar, sempre, sempre bem dispostos" (RG - corticeira - 86 anos).

De certa forma são também estas as recordações que vão contribuir para a construção de um passado mítico do qual se destacam valores como a amizade, o companheirismo e a cumplicidade: "Eu tenho muitas recordações boas da fábrica. (...) [À hora do almoço] dançávamos umas com as outras, fazíamos bailes e tudo. Cantávamos. (...) Mesmo já depois de casada fazia lá bailes e tudo e dançava. O meu marido não, não sabia. Para castigo, era uma dançarina fui casar com um homem que não sabia dançar" (RG - corticeira - 86 anos).

O espaço da fábrica é importante na definição do tipo de actividades lúdicas a desenvolver assim como no seu enquadramento, no fundo ele é um espaço estruturador das próprias relações sociais: "A fábrica ou a oficina é o mais importante espaço de sociabilidade, condicionando todos os restantes laços de solidariedade e coesão. Não será estranho a este facto a constatação de uma memória operária organizada geograficamente pela concentração fabril, ou por pertença a um mesmo sector industrial" (vários, 1996: 47). O espaço da fábrica constitui-se, assim, como ordenador da memória, descrito e recontado através de gestos e palavras, como suporte material da acção. 
Quanto ao quotidiano de trabalho, duradouro no tempo, que estas mulheres tiveram encontrasse marcado ainda hoje em situações de análise e apreciação da realidade que nos conduzem directamente para as fábricas. Permanece quase uma cosmovisão profissional quando deparamos com uma operária conserveira, afastada de uma fábrica há mais de vinte anos, que nos descreve minuciosamente como arranja e condimenta o peixe que consome em casa. Também faz apreciações acerca da qualidade do trabalho da indústria conserveira actual, chegando a referir que existem latas que nem sequer consegue comer. Com as corticeiras a situação repete-se, todas descrevem a má qualidade das rolhas actuais, que são por exemplo coladas e relatam "casos" de rolhas que vêem no dia a dia, fazendo observações minuciosas às suas boas ou más características. Os conhecimentos adquiridos durante anos na fábrica, continuam assim a fazer parte do quotidiano destas mulheres, moldando a sua acção e pensamento sobre alguns aspectos da realidade. Elas consideram-se especialistas de uma determinada área, criticando o presente em detrimento de um passado onde "se sabia fazer" e a qualidade, perfeição e empenho imperavam.

Por fim, nenhuma das facetas dos discursos que recolhi se anula ou exclui, antes se complementam na demonstração das diversidades interpretativas da realidade nos seus vários ângulos de observação. Não só cada pessoa pode ter e tem um olhar próprio sobre o que a rodeia, como esse mesmo olhar não é estático nem monolítico, não estando por isso a salvo de inconsistências internas que o tornam seguramente mais rico e interessante.

Neste processo de rememoração do passado não se encontra assim ausente uma certa mitificação em torno da experiência de trabalho na fábrica, que representou e representa de facto um eixo identitário fundamental e estruturante da vida destas mulheres. As ideias mais fortes e recorrentes são as de anulação da conflitualidade: "Mas naquele tempo não havia assim a crítica que há agora, não, não sei porquê mas naquele tempo parece que era tudo gente amiga, davam-se todos muito bem, não havia zangas, não havia nada" (EA - corticeira - 82 anos).

Olhando para trás muitas destas mulheres constróem assim lembranças harmónicas e destituídas de conflito, rememorando um determinado passado mítico onde a comunidade é idealizada. Esta lembrança deformativa do passado também incide sobre o próprio ambiente de trabalho, embelezando-o: "Eu cá tenho dito tanta vez, aquilo ardeu, mas se eles restaurassem aquilo tudo eu não me importava de ir para a fábrica que era a minha alegria ir para a fábrica. Era pesado, mas aquilo até era bom" (EL - conserveira - 75 anos).

E por fim, é exaltado um forte sentido de comunidade. A união, a fraternidade, a amizade são valores que remetem para o passado em oposição a um presente "falso", "artificial" e "desumanizado": "Sempre me dei bem com a gente daqui. Aqui era tudo uma lealdade pegada, a gente conhece-se uns aos outros. Conhecemo-nos uns aos outros. (...) A gente trabalhava, vivia na miséria, mas a gente tínhamos disposição para tudo e havia tudo lealdade. (...) Dantes havia muita lealdade" (AA - 
corticeira - 85 anos). A forma como se constrói uma determinada imagética regressiva, do que ficou lá atrás, vai reflectir-se depois claramente no tipo de sentimentos que presentemente se manifesta.

Neste caso em particular, este tipo de mitificação saudosista é muito interessante porque mais do que uma simples construção pessoal parece constituir-se como um labor colectivo, da própria comunidade. A mitificação do passado é um processo de (re)construção identitária, neste caso colectiva, que visa manter e reproduzir uma determinada imagem-memória da comunidade em causa. Ângela Luzia, no decurso do seu trabalho, depara com sentimentos saudosistas relativamente a um passado de prosperidade industrial, chamando a atenção para a questão da transmissão da memória às segundas gerações, trabalhadores maioritariamente do sector terciário, que não partilham do mesmo sentido de comunidade ou mesmo de classe dos seus pais ou avós. Segundo a autora (1996: 69), a comunidade operária perdeu protagonismo num palco onde dominava as técnicas de actuação, tanto em contacto directo com público como nos bastidores:

\footnotetext{
Hoje em dia o enunciado desta condição operária é referenciado no passado, uma vez que os maiores complexos fabris do concelho faliram, acabaram ou estão decadentes. É com nostalgia que se recorda quando tudo isto era um movimento, tudo a funcionar, em memória de um protagonismo hoje suplantado pelo terciário, sempre com a preocupação de que esta memória perdure nos mais novos, por via familiar e da escola.
}

No que diz respeito à classe corticeira, expoente máximo da resistência operária no concelho, tratase da construção de uma memória colectiva em torno do desempenho reivindicativo de uma das famílias operárias mais numerosas e importantes da zona. Não pretendo diminuir em termos significativos o verdadeiro e importante papel que esta classe profissional teve; existiram de facto inúmeras situações, em que os corticeiros se destacaram pela sua capacidade organizativa e de reivindicação que os tornaram no ícone da resistência operária em Almada. Cada corticeiro ou corticeira torna-se assim também num símbolo vivo que encarna valores e comportamentos de um grupo que vão para além da sua própria individualidade. Transformaram-se numa referência de autoridade para a comunidade, quando se trata de evocar acontecimentos do passado, principalmente se o fio condutor dessa evocação forem as questões ligadas à resistência operária.

Sobre o desempenho das mulheres corticeiras, algumas destas memórias certamente exageradas devem, no entanto, ser lidas à luz de uma imagética colectiva que procura entronizar os seus heróis, alimentando uma memória profissional que conjuga o tempo quotidiano, do trabalho fabril e doméstico, com os momentos de resistência e revolta.

\section{Bibliografia}

Almeida, Ana (1993). A Fábrica e a Família. Famílias Operárias no Barreiro. Barreiro: Câmara Municipal do Barreiro.

Namer, Gerard (1987). Mémoire et Société. Paris: Meridiens Klincksieck.

Halbwachs, Maurice (1925). Les Cadres Sociaux de la Mémoire. Paris: Félix Alcan.

(C) Inês Fonseca. Publicado en AIBR. Revista de Antropología Iberoamericana, Ed. Electrónica

Vol 1. Num. 3. Agosto-Diciembre 2006. Pp. xiii-xxi Madrid: Antropólogos Iberoamericanos en Red. ISSN: 1578-9705 
Halbwachs, M. (1997). La Mémoire Collective. Paris: Ed. Albin Michel.

Langness, L. L. e Frank, Gelya (1995). Lives. An Anthropological Approach to Biography. California: Chandler \& Sharp Publishers.

Luzia, Maria Ângela (1996). A Memória, A Cidade e o Rio. Tese de Mestrado, não publicada, Departamento de Antropologia, Faculdade de Ciências Sociais e Humanas.

Rosas, Fernando (1995). Portugal entre a Paz e a Guerra (1939-1945). Lisboa: Estampa.

Cole, Sally (1994). Mulheres da Praia. Lisboa: Dom Quixote.

Roberts, Elizabeth (1984). A Woman's Place: an Oral History of Working-Class Women. 1890-1940,

Oxford/Cambridge: Blackwell.

Gillis, John (1974). Youth and History: Tradition and Change in European Age Relations, 1770 - Present, New York: Academic Press.

VV.AA. (1996). Memória e Identidades Profissionais. Reprodução de Sistemas Sócio-Técnicos, Lisboa, Faculdade de Ciências Sociais e Humanas, relatório final de projecto PRAXIS / PCSH / ANT / 0044 / 96 - não publicado.

Zonabend, Françoise (1980). La Mémoire Longue. Paris: Presses Universitaires de France. 